The final, definitive version of this paper has been published in Business Communication Quarterly Vol 71 Issue 2 Pages 171-183, June 2008 by SAGE Publications Ltd. All rights reserved. (C SAGE

http://bcq.sagepub.com/cgi/content/abstract/71/2/171

\title{
EXPRESSIVE PRACTICES: THE LOCAL ENACTMENT OF CULTURE IN THE COMMUNICATION CLASSROOM
}

\author{
Karen Wolf \\ Suffolk Community College, State University of New York \\ Trudy Milburn \\ California State University, Channel Islands \\ Richard Wilkins \\ Baruch College, City University of New York
}

Abstract: As students participate in corporate communication classes, they may, on occasion, use the term culture to make sense of their experiences. The authors use Mino's idea of a learning paradigm to shift the emphasis away from teaching traditional theories of culture and use student-centered experiences to teach culture as an expressive practice. Using instances drawn from their own classrooms, the authors show how students can recognize the value of understanding their role in creating culture each time they choose how to act, how to evaluate others' behavior, and whether to label what is going on as cultural.

Keywords: intercultural communication; organizational communication; pedagogy; identity

As a response to the strong current carrying culture in new directions, we embarked on a research endeavor to explore the challenges we felt, as instructors, to more carefully define and delineate how we teach the concept of culture. The objective of this article is to propose an alternative treatment to the concept of culture, one that suggests an expressive quality that encourages students to think critically about basic beliefs related to how people and business settings operate. We examine specific instances of student communication to assess how the process of communication about culture affected interaction in specific classroom situations. Based on this analysis, we identify a pedagogical strategy that incorporates and builds on the need to reconsider the ways and means by which we utilize the term culture in our classrooms, specifically focusing on what Mino (2001) describes as a learning paradigm. That is, we shift the emphasis away from teaching traditional theories of culture to our students and propose instead the use of student-centered theories of culture-those that make sense to students based on their own experiences.

In our review of recent literature exploring culture in the classroom, we found several articles that described one teaching goal as fostering a shared culture (Holmes, 2004; StarkeMeyerring, \& Andrews, 2006; Zhu, 2007). However, these articles do not reflect on what a "culture" is, nor do they offer explicit definitions of culture. In some cases, discussions of culture seems to indicate people from different countries but do not detail how particular countries may have cultural differences present within their own populations. When culture is defined, it is often described as including rules or norms for action, rituals, symbols, and values. 
These dimensions of rituals, symbols, and values are explored by instructors in various assignments given to students, which can include completing case studies, analyzing a conversation, and emailing a questionnaire and collecting the respective responses. However, the way rules or norms are used or are manifest as a key part of communication is not mentioned. Of those articles that explore the use of culture in the classroom, Grosse (2002) has suggested students become more "sensitive" to cultural differences by having mutual "trust" and "respect" and valuing "diversity" for additional perspectives and creativity in completing work projects. Other articles have proposed ways to incorporate cultural learning norms into the classroom (Speece, 2002) and explored different business cultures (Evia, 2004) yet do not explicate much about those differences.

In our study, we argue that teaching culture matters because it calls into question existing definitions of culture and because we use the idea of the classroom culture as a way to become self-reflexive. Most of the articles we reviewed explore assignments that get students either to learn about other cultures or to create intercultural communication within one class-often virtually collaborating with another country. Our study offers a way to look at the definition of culture as it occurs in practice among students in the classroom. At the same time, it calls into question the reflexive nature of the use of culture both through talk and application. $A$ pragmatic and reflexive view of culture is something teachers at all educational institutions can benefit from as they plan for lessons incorporating issues related to culture.

\section{CULTURE AND THE CLASSROOM: THE SITUATION AT ONE URBAN COLLEGE}

Our motivation for carrying out this project is based at least partly on examples gathered in and out of the classroom from our students at an urban college in New York City. One striking observation is the claim by some students that culture is no longer a viable concept because the college community is so diverse that we should try to transcend matters of culture and its divisionary bias. Like many urban institutions, this particular institution has been recognized as one of the most ethnically diverse institutions of higher education in the United States (U.S. News \& World Report, 2007).

One of the challenges we faced as faculty teaching this particular student body included how to teach the concept of culture to a group of students who live an intercultural life. As instructors, we considered problems such as whether or not we should be constantly revising our syllabi based on the life circumstances of the students we are teaching. For instance, when teaching in an urban academic institution in New York City, how should we respond to the following sentiment: "Culture is no longer a viable concept since we deal with folks from all over the world every day. Why do we need to learn about intercultural communication?" Do we tell students, "We are teaching intercultural communication to you so that you can interact with people in areas where there is a great deal of homogeneity"? Alternatively, in another less diverse setting, if presented with the question, "Why do we need to learn about other cultures? We're all the same here," do we respond to the students by saying, "You should learn this way of conceptualizing culture, so when you go to a place like New York City you know how to interact with others and there will be fewer breakdowns in communication"? 


\section{CULTURE AS AN EXPRESSIVE PRACTICE}

To facilitate the discussion of culture as it is relevant to our current students, we found it helpful to first distinguish between the emic and etic uses of the term. Pike (1967) introduced the notion of etic and emic to differentiate between research that examines data from a very close, detailed, behaviorally specific perspective (emic) and research that seeks to examine broader, general trends (etic). Carbaugh, Gibson, and Milburn (1997) offer yet another way to conceptualize the etic-emic framework: One can think of the emic as a "turtle's eye" or close view and an etic as a "bird's eye" or far view of a culture. To illustrate the emic and etic uses of culture, we explore how analysts of communication use these concepts and also how a local understanding of culture is incorporated into organizational discourse. More particularly, in this article, we provide extracts that demonstrate pedagogical moments when the term culture is shown to be both a relevant and a prominent concept for students of communication in one urban educational institution. The suggestion that culture is no longer a necessary concept is one that presupposes a merged emic-etic use of the term where there should be two separate and distinct categorical uses and understandings. That is, culture might not have utility for scholars in all situations, yet it is far from obsolete in its local usage-for these students, the term culture is very rich when it is in use.

Toward this end, we address questions that ask

1. What are the prominent ways theorists and students talk about culture?

2. Where are the intersections between theoretical and local uses of culture?

Our research questions are largely driven by our experience teaching cultural and intercultural communication concepts to students at one college in New York City.

Throughout the traditions that make up the social sciences, scholars use the concept of culture to organize their findings. We choose to focus on those authors who conceive of culture as a process rather than a ready-made, static entity. The definition of culture that we use resonates with one that argues culture is emergent through dialogue, yet not "reducible" (Tedlock \& Manheim, 1995, p. 9) to the people who are interacting. That is, one can look at culture as it is enacted through the communication events one has, yet culture has an element to it where it retains some of its shape. For us, this means that in an etic sense we can discuss some features that exist culturally; but in an emic sense, culture is going to emerge through interaction (Tedlock \& Manheim, 1995, pp. 8-12). We borrow from Carbaugh (1996), who explains a discursive practice as "an actual means of expression in a community, given that community's specific scenes and historical circumstances" (p. 14). We may be starting with the etic interest of culture but are quickly able to realize the local emic concerns of culture active in student discourse.

In our examination, and to go from description to interpretation, we need to add a layer that includes the "meaning" of culture. Researchers in various disciplines including anthropology, rhetoric, and communication have described the way that meaning relates to culture. For instance, Geertz (1973) takes a "semiotic" approach that defines culture as having to do with creating meaning through communication. What counts as culture are the "symbolic dimensions of social action" (Geertz, 1973, p. 30). Later, Geertz (1987) refines his notion of 
culture as an assemblage of texts. In addition to symbols and texts, Farrell (1993) defines culture as "the common definition of places for the invention and perpetuation of meaning" where those who "live in it" use "symbols and families of practices that permit ongoing performances of meaning and value" (p. 277). Schneider (1976) offers a holistic definition of culture as a "system of symbols and meanings" and "an irreducible analytic construct" that is "best understood through observable behavior" (p. 198). In contrast, Baumann (1996) urges us to reconsider the use of the term culture as an all-inclusive category and suggests that we focus more on particular subsets or communities. He states, "The variety of community definitions would appear to offer strong evidence that communities are processually constructed, rather than found as the ready-made social correlates of consistent and bounded cultures" (p. 191). These theoretical definitions of culture are interpretive resources that we add to the specific definitions found in our textbooks.

In our organizational communication courses, the literature about organizational culture is presented in the textbook and by the instructor. A primary model for examining cultures is the one set forth by Deal and Kennedy (1982) or that of Schein (1991). Deal and Kennedy describe organizational cultures as being composed of six components: (a) location, (b) mission statement/values, (c) heroes/corporate leadership, (d) rites/rituals, (e) communication networks, and (f) stories/myths. Schein describes organizational culture as that which is "enacted" rather than existing as an external concept apart from the organization where it is studied. Although Schein is critical of what he terms the vague methods that examine common systems of meaning, he does suggest that researchers tie organizational parts into a larger gestalt. Schein advances the idea that the concept of culture helps us to understand (a) stability over time, (b) similarity or sharing among members, (c) patterned behavior, (d) the historical process of culture as it is enacted, and (e) influences on all areas of life. Therefore, Schein's definition of culture includes

a pattern of shared basic assumptions, invented, discovered, or developed by a given group, as it learns to cope with its problems of external adaptation and internal integration, that has worked well enough to be considered valid, and, therefore, is to be taught to new members of the group as the correct way to perceive, think, and feel in relation to those problems. (p. 247)

Although stemming from various disciplines within the social sciences, these definitions share the following features: (a) Culture is symbolic, (b) people enact and create culture through symbols and forms, (c) cultural symbols and meanings vary amongst people within different communities and within the same community, and finally $(d)$ culture is an ongoing process. It is the third and fourth claims that provide us with a basis for contending that we need to consider how to incorporate the term culture in new ways in our communication classrooms. Herein, we argue there is a need to shift the focus of culture to be more an outcome of analysis that we can point to-be that through participant interpretation or social scientific research-rather than a demonstrative concept that is posited a priori. 


\section{CASE STUDIES DRAWN FROM THE CLASSROOM}

To begin a discussion of some localized expressive uses of the term culture, we turn to some examples taken from our classes. Each of us have taught courses in a communication department that acts as a service department by teaching public speaking to the entire student body. In each of our communication courses, the issue of culture has frequently presented itself among our ethnically diverse student body. One common discussion has revolved around nonverbal acts of communication and in particular the notion of eye contact. In one class, the discussion was based on issues of respect that are attributed to or garnered by people because of eye contact. Members of some cultural groups demonstrate respect by not making eye contact when listening, whereas members of other cultural groups interpret this behavior as a lack of respect. In response to a discussion about nonverbal communication and assimilating into an organizational culture, Student A provided the following example.

\section{Extract 1}

Student A: In her job at [name deleted] organization, a female Muslim employee was approached by someone from Human Resources and asked to make eye contact with all customers she interacted with. The employee claimed she was uncomfortable, but agreed to do it anyway. This employee had to "learn" to make eye contact with all people and that it was difficult for her, especially with men. I really felt bad for her.

In reacting to this story, Student B replied as follows:

\section{Extract 2}

Student B: I work for a law firm and you can't do that [tell someone to make eye contact]. I'm telling you that's a lawsuit right there. You can't do that-you have to recognize different cultures have different ways of doing things.

There are laws about that. That's why there's diversity training.

Student A: [Nods in agreement, along with many others in the class.]

These extracts demonstrate that, at one level, the term culture is used as a label. First, the instructor questions the class about organizational culture. Then, to make local sense of this, Student A provides an instance whereby one organizational culture insisted on a change in practice by someone who lived by recognizably different cultural practices. These emic descriptions demonstrate that culture is a locally useful term that helps students refer to and understand the kind of demands that employers may ask of them as employees and how to discuss such instances with others in a classroom. The discussions of culture in Extracts 1 and 2 exemplify the important role that history and personal circumstance play in discursive practice. What is culturally meaningful here is based on access to a historical past and a value system particular to the participants.

The topic of diversity was introduced during one undergraduate class discussion. While querying students about diversity, the instructor sensed that they appeared to be reticent to discuss differences between people. To paraphrase, 


\section{Extract 3}

Instructor: What do you believe are the features of culture? What are some examples of culture here at our college?

Student A: Traditions.

Student B: Norms and rituals.

Student C: At this college, we are all students with different cultural backgrounds. If someone does not speak up in class, then it is that person's business. It may have to do with her culture, but anyone can do what she wants. Instructor: Well, if there are certain people who don't speak up in groups, either because it is their individual preference or based on some cultural practice, then how do you, as their team members, get them to participate [recognizing that group participation is valued for teamwork]?

The preference was for students to describe themselves as "all in it together" and as "all people" rather than as different people belonging to different cultural groups. Although some students were able to give examples of particular ways of speaking that are culturally distinct, they seemed to have a preference for attributing these differences not to culture but rather to individuals who happen to have different ethnic or religious backgrounds (see Wilkins, Wolf, \& Milburn, 2005).

In the examples presented above, and a variety of other instances, such as undergraduates who do not self-identify cultural background(s) when they are talking about practices and beliefs and public speaking students who identify their cultural background as appeals for arguments, we hear and see "culture" enacted locally. Again, Extract 3 provides a particular instance of students reflecting on culture as they talk to one another. Participants draw on their own set of beliefs and values to help articulate why and when culture matters.

\section{ANALYSIS OF THE DIALOGUE OF CULTURE}

In terms of the meaning for such cultural practices, we can hear in the examples above a strong preference to maintain certain practices of communication that are more longstanding (and perhaps deeply felt) than to take on new practices of communication that are prescribed by a new setting. This reaction is particularly strong if an organizational culture asks a person to distance herself or himself from a belief or value that is intimately linked to an ethnic or religious culture. This is why one participant suggests that there are laws to protect persons from being asked to change their cultural ways to meet the needs of a new and different setting. Regardless of preference, however, there is utility to the term culture for making sense of what one can and cannot be asked to do as well as what one is bound to do or chooses to do. It is through the dialogue about this situation that culture becomes meaningful for the participants, that is, the students and instructors.

As instructors listening to and watching the emerging discourse of our classrooms, we found ourselves examining the students' expressive use of the term culture. Culture became a central frame of reference for students because it responded to questions revolving around the construction of social realities. Such a frame of reference relocates a static conceptualization of 
culture into an expressive practice. Hence, we began to listen for sayings that validated, denied, or created a sense of culture. What is suggestive of such a frame of reference is that "the features of a given society's social structure influence both the course of conduct in observable social events and the scenarios of its genres of cultural performance" (Turner, 1980, p. 142).

The emphasis is then placed on the constitutive use of language, that language gets linked to its context of use. Hymes $(1964,1974,1983)$ has written extensively about the notion of communicative competence, where, in addition to a grammar, a person of a given speech community "acquires also a system of its use, regarding persons, places, purposes, other modes of communication, etc.-all the components of communicative events, together with attitudes and beliefs regarding them" (Hymes, 1974, p. 75). Communicative competence refers, then, to the ability of a member of a given community to use language in a socially appropriate manner. Notions of context relative to the speaker(s) define the socially appropriate. Language is not only dependent on its situation of use but also fundamentally creates that situation. Typically this approach is named as a constitutive rhetoric (Charland, 1994). In Extracts 1 and 2 above, culture is being used to refer to someone's ethnic or religious background as an indication of how one is expected to act or communicate. Student B is able to identify the issue as one that is culturally based. In these examples and the next, part of the tension stems from the recognition of an alternate cultural belief system that seems to hold a hierarchal position related to how one accounts for actions.

Throughout Extract 3 and other discussions similar to it, the class discussed the idea of culture as unified and the idea of an organizational culture that includes many people from different cultural backgrounds. After asking if there is anything that students have in common, one student stated, "We are all here to get our degree so we can get good jobs." Initially, students describe their college as a place with many cultures. What they are usually referring to is the ethnic or national cultural backgrounds of the students. When we discuss more about the common goals of students, we often learn that the students as a whole are enrolled at this school because of its business school reputation and that gaining a college degree will help them succeed financially. This example relates to a common sentiment among instructors at one particular urban institution that can be heard among students: Culture or cultural differences among students do not matter much ("We're all here, we deal"). Although this line offers a glimpse of student life for students in a setting whose diversity is taken for granted, it also mutes the tensions arising from attempting to describe value-specific cultural differences in workplace or classroom settings.

\section{THE CONVERSATIONAL DYNAMICS OF CULTURE}

From the vantage point of culture as an expressive practice, we present culture here as something that is created by and subjected to conversational dynamics. This approach toward the understanding of culture does essentially three things:

1. There is a relocation of culture into practice. Culture, in its emic sense, becomes important only if we hear sayings that state that it is important (as with the female employee in Extract 1).

2. Culture is treated as something validated, denied, or created in context (as in 
Extract 2, when a student says diversity training is provided to help recognize cultural difference).

3. Culture is treated as a result or dynamic of communicative practice (e.g., when students discuss what is culturally diverse among them, as they do in Extract 3).

For educational institutions in general, the ideas noted in this article have importance for the following reasons. First, using this understanding of culture in our classrooms illustrates what Mino (2001) has described as the fifth dimension of the learning paradigm, namely shifting from an emphasis on "access" for diverse classrooms toward student "success" based on students' own cultural points of view. And second, students come to appreciate culture as an expressive practice that is created in context and as a result or dynamic of communicative practice.

It follows that one way to shift from access to success in the learning paradigm would be to use student experiences to track dynamics of expressed culture. These experiences may come in the form of expressed social, regional, and national identities; they may come in the form of students questioning nonverbal actions or organizational identities. As these dynamics interact, we can suggest that every communication system makes available, and values, some expressed aspects of culture over others. Thus, we have the foundation for an understanding of culture as a practice that has theoretical and practical implications for readers in relation to their own activities for the classroom.

As instructors, one of our goals is to help students to use theoretical language to understand their communication practices. One attempt has been to offer three distinct perspectives of culture: integration, differentiation, and fragmentation (Frost, Moore, Reis Louis, Lundberg, \& Martin, 1991). The first is the common view of culture as cohesive and consistent across members (shared beliefs and values). The second describes cultures as a combination of consistency and inconsistency where many subcultures coexist. The final perspective focuses on the ambiguity and fluctuation prevalent in cultures where multiple interpretations exist that are often inconsistent and contradictory. By examining the culture of any lived experience of a student through these three perspectives, one begins to see the tension that arises from considering culture as either having a strong, cohesive structure or being composed of smaller groups or ambiguous symbols. Although the fragmentation and differentiation perspectives foreground fluidity and change, they do not foreground communication. We contend that taking communication to be our unit of analysis can create a variety of kinds of cultures-from cohesive to fragmented. By examining the expressive process itself, researchers and students learn more about the patterned ways of interacting differently (distinctly) and learn to be sensitive to these differences - rather than assuming a common way of communicating - even when hoping to create a cohesive, common culture. As a local, emic term, culture provides a way for students of communication to make sense of the communicative experiences they have in the workplace (e.g., eye contact), the classroom (e.g., discussing diversity), and throughout pedagogical decisions (e.g., how we as instructors facilitate these discussions). As an etic term, culture provides a way for students to look to the larger contextual features of situations and determine that may operate to create cohesion or differentiation. However, the focus is always on the actual practices enacted by participants (students, employees, instructors) and not on a 
mythical group that holds the cultural standards and that moderates and grades behavior as conforming and not. This approach resonates with our objective in shifting toward a more learning-centered paradigm.

In sum, we agree that culture is changing and fluid, yet this dynamic can be observed only in specific instances where the student becomes the center of our theoretical discussions. Recognizing the participative nature of culture is a way to help teachers and students recognize the value of understanding their role in creating culture each time they choose how to act, how to evaluate others' behavior, and whether to see or label what is going on as cultural.

\section{References}

Baumann, G. (1996). Contesting culture: Discourses of identity in multi-ethnic London. Cambridge, UK: Cambridge University Press.

Carbaugh, D. (1996). Situating selves. Albany: State University of New York Press.

Carbaugh, D., Gibson, T. A., \& Milburn, T. (1997). A view of communication and culture: Scenes in an ethnic cultural center and a private college. In B. Kovacic (Ed.), Emerging theories of human communication (pp. 1-24). New York: State University of New York Press.

Charland, M. (1994). Constitutive rhetoric and the peuple Quebecois. In W. Nothstine, C. Blair, \& G. A. Copeland (Eds.), Critical questions (pp. 206-232). New York: St. Martin's.

Deal, T. W., \& Kennedy, A. A. (1982). Corporate cultures: The rites and rituals of corporate life. Reading, MA: Addison-Wesley.

Evia, C. (2004). Technical communication learning on the U.S. Mexico border: Factors affecting cross-cultural competence in globalized settings. Business Communication Quarterly, 67, 233-237.

Farrell, T. B. (1993). Norms of rhetorical culture. New Haven, CT: Yale University Press.

Frost, P. J., Moore, L. F., Reis Louis, M., Lundberg, C. C., \& Martin, J. (Eds.). (1991). Reframing organizational culture. Newbury Park, CA: Sage.

Geertz, C. (1973). The interpretation of cultures. New York: Basic Books.

Geertz, C. (1987). Deep play. In P. Rabinow \& W. M. Sullivan (Eds.), Interpretive social science: A second look (pp. 195-240). Berkeley: University of California Press.

Grosse, C. U. (2002). Managing communication within virtual intercultural teams. Business Communication Quarterly, 65(4), 22-38.

Holmes, P. (2004). Negotiating differences in learning and intercultural communication: Ethnic Chinese students in a New Zealand University. Business Communication Quarterly, 67, 294-307.

Hymes, D. H. (1964). Language in culture and society: A reader in linguistics and anthropology. New York: Harper \& Row.

Hymes, D. H. (1974). Foundations in sociolinguistics: An ethnographic approach. Philadelphia: University of Pennsylvania Press.

Hymes, D. H. (1983). Essays in the history of linguistic anthropology. Amsterdam: John Benjamins.

Mino, M. (2001). Shifting from an instructional to a learning paradigm: Some options for communication educators. Qualitative Research Reports in Communication, 2, 14-23. 
Pike, K. (1967). Language in relation to a unified theory of the structure of human behavior. The Hague, the Netherlands: Mouton.

Schein, E. H. (1991). What is culture? In P. J. Frost, L. F. Moore, M. Reis Louis, C. C. Lundberg, \& J. Martin (Eds.), Reframing organizational culture (pp. 243-253). Newbury Park, CA: Sage.

Schneider, D. (1976). Notes toward a theory of culture. In K. Basso \& H. Selby (Eds.), Meaning in anthropology (pp. 197-220). Albuquerque: University of New Mexico Press.

Speece, M. (2002). Experiential learning methods in Asian cultures: A Singapore case study. Business Communication Quarterly, 65(3), 106-121.

Starke-Meyerring, D., \& Andrews, D. (2006). Building a shared virtual learning culture: An international classroom partnership. Business Communication Quarterly, 69, 25-49.

Tedlock, D., \& Manheim, B. (1995). Introduction. In D. Tedlock \& B. Manheim (Eds.), The dialogic emergence of culture (pp. 1-32). Urbana: University of Illinois Press.

Turner, V. (1980). Social dramas and stories about them. Critical Inquiry, 7, 141-168. U.S. News \& World Report. (2007). America's top colleges 2007. New York: Author.

Wilkins, R., Wolf, K., \& Milburn, T. (2005). Teaching "culture" as an expressive practice. Texas Speech Communication Journal, 30, 86-88.

Zhu, Y. (2007). Using authentic cross-cultural dialogues to encourage international students' participation in tutorial activities. Business Communication Quarterly, 70, 43-47.

Karen Wolf, $P h D$, is an assistant professor of communication and academic chair of the Humanities Department at Suffolk Community College, State University of New York. Her research on cultural communication and rhetoric is published in various communication journals. Address correspondence to Karen Wolf, Suffolk Community College, Department of Humanities, 121 Speonk-Riverhead Rd., 126 Orient Building, Riverhead, NY, 11901; email: wolfk@sunysuffolk.edu.

Trudy Milburn, PhD, is an associate professor at California State University, Channel Islands. Her research about culture, discourse, and collaboration has been published in a number of journals and edited volumes. Her book, Nonprofit Organizations: Creating Membership Through Communication, is forthcoming. Address correspondence to Trudy Milburn, Communication, California State University, Channel Islands, One University Dr., Camarillo, CA 93012; email: trudy.milburn@csuci.edu.

Richard Wilkins, PhD, is an associate professor at Baruch College, City University of New York. He teaches research methodology and interpersonal, small-group, and intercultural communication. He has published several case study analyses and methodological advances in the ethnography of communication. Address correspondence to Richard Wilkins, Department of Communication Studies, Baruch College, CUNY, One Bernard Baruch College Way, New York, NY 10010; email: richard_wilkins@baruch.cuny.edu. 